\title{
Study on the Specific Application of Multimedia Research in PE
}

\section{Teaching}

\author{
Xuanjie Zhou $^{1}$, Qing Sun ${ }^{1}$ \\ ${ }^{1}$ Nanchang Institute of Science and Technology, Department of Physical Education, Nanchang, \\ Jiangxi , 330108 \\ 346591653@163.com
}

KEYWORDS: Multimedia Technology; PE Teaching; Specific Application

\begin{abstract}
The 21st century is an information age, the rapid development of the twenty-first century is the era of multimedia technology. Multimedia era for the community, the country has brought great benefits, but also on the national education put forward new challenges that require the use of multimedia technology, the full implementation of digital education. Multimedia teaching is an extension of the use of a model out, convenient, fast, simple, easy to operate, and so this is the impact of multimedia teaching to bring the Chinese Education. In this paper, PE teaching, for example, do in-depth research and analysis on specific media in PE teaching.
\end{abstract}

\section{The Specific Application of Multimedia in Teaching PE}

\section{A. The Specific Application of Multimedia in PE Classroom Teaching}

Multimedia teaching is intuitive and easy to operate and convenient. This is the twenty-first century, the development of multimedia technology era inevitable trend. The use of multimedia technology teaching, so that students can feel a strong intuitive learning environment, multimedia is mainly used in the classroom by making learning courseware, with pictures, video and other learning courseware as an auxiliary to enhance students' interest in learning, rich learning content.

First in PE Teaching Learning Courseware, you can use multimedia technology to produce a devoted sports teaching advantages and benefits of sport can bring people to explain why the sport to learn the layout, the popularity of sports knowledge to students; secondly, a lot of more well-known at home and abroad to collect photos of sports stars and sports experiences through their events with the sports teaching content, not only to improve students 'physical education teaching learning fun, but also to ease the mood PE caused boring, deepen students' physical education teaching understanding of knowledge. Then in the process of physical education in the use of multimedia technology can occasionally make some funny video, collect some humorous interludes relaxing sound image in the teaching content, increase the vitality of sports classrooms, but also improve the quality and efficiency of learning Physical Education.

After completion of PE teaching courseware, teaching can be put to use. PE teaching courseware main purpose is to conduct classroom students supporting role, with the teacher's careful to explain, elaborate one by one, the effect of the classroom will be able to achieve a very high level. Of course, in the process of classroom instruction, you can not just go exactly as courseware, teacher occasionally also need to use multimedia technology to students 'physical education learning contents do extend and broaden students' knowledge and awareness. Through teaching experiments 
show that within the courseware class teaching, first attracted the attention of students, 99 percent of students did listen carefully. Secondly, the teaching effect is significant, 95 percent of students do skilled recite the essentials and formulas, the outer class teaching, $85 \%$ of the students action norms, $12 \%$ of the students be able to do basic grasp, only $3 \%$ of students did not technology to complete the action.

Classroom interaction and learning interaction among students and between teachers and students is an important point Physical Education. Previous classroom interaction between teachers and students are mostly raised his hand, the teacher named in the statement or ask a teacher, students answer one, this interactive way too old classroom, the students are not interested. Use of multimedia technology has changed the old classroom interaction, not only between teachers and students in the classroom interaction, but also after-school, but also a lot of expression package used to increase interaction between the fun, or cute, or shy, or angry, or confused, etc., interaction between teachers and students is no longer boring, no sense of restraint. And between students can also promote feelings between the students through interaction in such a way, learn from each other.

In addition, the interaction between teachers and students before most of the students do not know where, when the question is raised, the teacher will have to answer, which is the unity of all occupied classroom time to answer this question perhaps some students will have a does not require the teacher to explain again, then for these students is a waste of time, the use of multimedia technology can change this situation, have questions, you can point directly to the desktop icons show of hands, the teacher's computer can directly control the student's computer, the teacher in question for students to explain their individual and counseling, it is a question of the students questions resolved, the rest of the students can use this time to arrange their own time.

\section{B. The Specific Application of Multimedia in Teaching and Training}

In physical education training is an essential part, is also very important teaching point. For example, the $400 \mathrm{~m}$ sprint training, physical education and training after the first, after a period of rest, the second time physical education and training, the students start training again, students may stay on sprint posture training, or teachers feel that students in the sprint posture training qualified to enter the next phase of training on the arrangements for the next phase of the study, there is no comparison do not know how effective the training is not an accurate measure of whether students advance to the next stage of training. The use of multimedia technology can help teachers keep records of students' physical training situation, teachers can train students by recording situation weekday measure whether students training objectives and requirements and teacher can accurately determine whether the student can proceed to the next stage of training. And by comparing the results of each training session, students can identify weaknesses and focus on training students 'weaknesses, improving the quality of students' physical training.

The use of multimedia technology to every student's training results are complete record, entered into the computer, and organized into a set of data, then the use of computer software for student sports scores were analyzed, together with the students' physical training situation, a comprehensive two the results were analyzed, and ways to improve the training, organized into a complete and comprehensive physical education and training information feedback system, which is the students' physical education and training of great help.

The use of multimedia technology to every student sports training process recorded and entered into the computer, then carefully packaged and integrated to produce a complete set of physical education and training learning courseware to facilitate future physical education. Secondly, in order to achieve better physical education and training effect, you can use multimedia, multi-collection and even abroad to find excellent courseware school physical education and 
training around the world, multi-view of these outstanding physical education and training courseware, learn to analyze , use, integrate, refine, to improve China's sports teaching and training courseware, improve the domestic level and quality of physical education and training.

\section{Limitations Exist in Specific Application of Multimedia Sports Teaching}

It called a coin has two faces, specifically the use of multimedia in physical education but it is for the domestic physical education brings many advantages, domestic physical education has great positive role in promoting, but in multimedia in Physical Education specific use of the important issues demonstrated the limitations, but also can not be ignored, it is worth attention needs to be improved. Because we have to straighten out a concept: the use of multimedia teaching, teaching for sports, this is only a relative good teaching methods, the effect achieved is to optimize the quality of teaching sports, is not perfect.

Physical education is unique, special manifestations mainly to theoretical teaching in other subjects, mainly through the active brain thinking, and actively develop their imagination to deepen students' learning effect and impression, to enter in-depth study; PE teaching go It is not a positive start teaching route brain thinking activity, but more emphasis on physical exercise. Physical exercise must personally demonstrate action by teachers, students follow suit, which is not currently teaching multimedia technology to achieve state. Although multimedia video teaching sector action points need to explain, but it lacks of correction and the actual operation of the instructor. Therefore, multimedia sports teaching can not replace all the traditional sports teaching methods. Need multimedia teaching and traditional teaching two modes fusion, using both mergers.

This in turn could explain the ever-changing patterns of teaching, there is no constant teaching mode, you can not use a fixed teaching mode, otherwise have a serious adverse impact on teaching. In the actual teaching, the teacher not only to fully consider the appropriate course content for students, and more important to individualized, requires a multifaceted approach in order to better measure, such as the ability to take full account of learning, individual differences in students' overall student and so on. Making multimedia courseware is based on the overall level of students on the basis of which some students may be lower than the overall level, and some was higher than the overall level, uneven, it is not unified classroom teaching mode, on the basis of upper, lower than the overall level of the individual student's individual counseling again, to explain.

Everything had to have a degree, both to help teachers use multimedia teaching, but can also affect teachers teaching. Multimedia information can accommodate very large, and very rich teaching resources, which for the teacher, in the choice of teaching content and there is a big problem on the difficulty to grasp the content, teaching content and more, students not cope, poor learning outcomes; content is difficult, and students together difficult, inefficient.

\section{REFERENCE:}

[1] Su Qingfang Computer Assisted Instruction in physical education specific implementation analysis [J]. electronic test, 2014,13: 145-146.

[2] Zhang Lei. Research on Multimedia Technology in College Physical Education Teaching [D]. Sichuan University, 2005.

[3] LI Guozheng, Liu Qi PE Teaching modern multimedia technology [J]. Beijing Agricultural College, 2007, S1:. 147-148.

[4] Zhang Weidong.i to the advantage of multimedia technology and strategies used in Physical Education [J]. Physical Education Institute of Shanxi Normal University, 2005,02: 90-92. 
[5] Li Guozheng, Liu Qi. PE teaching the use of modern multimedia technology [A]. Urban Agricultural Higher Education Teaching Papers album, 2007: 2. 